\title{
MODELING OF FLOW THROUGH A VERTICAL PERFORATED PIPE IN THE BEACH, AND THE MORPHODYNAMIC INTERPRETATION: THE PRESSURE EQUALIZATION MODULE SYSTEM
}

\author{
Fredsøe, Jørgen
}

Published in:

Proceedings of Coastal Dynamics 2009

Publication date:

2009

Link back to DTU Orbit

Citation (APA):

Fredsøe, J. (2009). MODELING OF FLOW THROUGH A VERTICAL PERFORATED PIPE IN THE BEACH,

AND THE MORPHODYNAMIC INTERPRETATION: THE PRESSURE EQUALIZATION MODULE SYSTEM. In Proceedings of Coastal Dynamics 2009 (Vol. Chapter 40). World Scientific.

\section{General rights}

Copyright and moral rights for the publications made accessible in the public portal are retained by the authors and/or other copyright owners and it is a condition of accessing publications that users recognise and abide by the legal requirements associated with these rights.

- Users may download and print one copy of any publication from the public portal for the purpose of private study or research.

- You may not further distribute the material or use it for any profit-making activity or commercial gain

- You may freely distribute the URL identifying the publication in the public portal 


\title{
MODELING OF FLOW THROUGH A VERTICAL PERFORATED PIPE IN THE BEACH, AND THE MORPHODYNAMIC INTERPRETATION: THE PRESSURE EQUALIZATION MODULE SYSTEM.
}

\author{
Jørgen Fredsøe ${ }^{1}$, Peter Engesgaard ${ }^{2}$ and Per Sørensen ${ }^{3}$
}

\begin{abstract}
It has been suggested that vertical perforated tubes placed below the beach surface will increase the drainage of the beach, and hence increase the deposition of sand on the beach. The system is called the PEM-system, Pressure Equalization System, and the Danish company SIC (www.shore.dk) is doing the marketing. Although it for a coastal engineer seems obvious that such a device can't drain the beach (nearly no driving forces ), SIC has succeeded in installing the system in more than 75 locations around the world (according to the company). In Denmark a full scale experiment at the exposed west coast has been performed through 2005-08, and a similar Dutch test is going on right now at Egmond, Holland. In this paper, we model the flow in the beach taking into account the presence of (high-permeable) tubes and demonstrate that the drainage effect is negligible. Further, the morphodynamic behavior of the coast in relation to the Danish field test is described, and it is concluded that all morphological changes can be explained by natural causes.
\end{abstract}

Key words: coastal protection, drainage, morphodynamics

\section{Introduction}

Drainage of a beach is known to have a stabilizing effect on the beach as depicted in figure 1 .

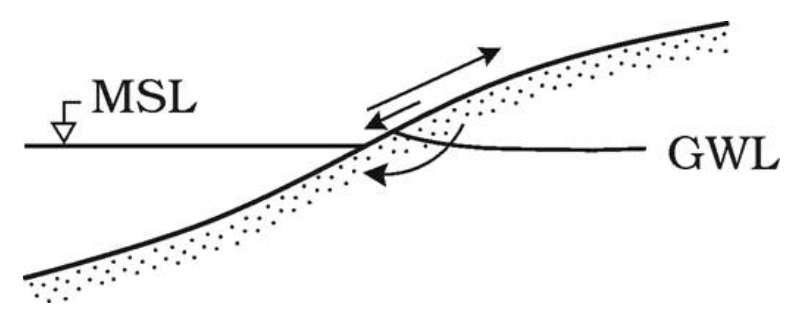

Figure 1. The flow is stronger in the run-up phase than in the backwash-phase if the beach is drained, because some of the run-up water can filtrate into the beach.

You can divide the drains into two types: Active drains with pumps installed to remove the water like the one shown in figure $2 \mathrm{~A}$ : The beach water is drained to the tube, and the water is transported further away by using pumps, thus creating a low pressure in the tube. Because you actually are pumping water away from the tubes, this is in the category "Active drains". The BMS has demonstrated some success: a small berm of beach sand is accumulated in the neighbourhood of the tube. The size of the berm depends strongly on local conditions, but the magnitude of accumulated sediment is $1-10 \mathrm{cbm}$ per meter beach. Bowman et al recently (2007) reported the use of BMS in Italy on a not very exposed beach West of Genoa. They observed a locally increase of $30 \mathrm{~cm}$ in one year on the drained beach as compared to the control section.

${ }^{1}$ Dept. Mechanical Eng., Technical Univ. Denmark jf@mek.dtu.dk.

${ }^{2}$ Dep of Geography and Geology, University Copenhagen pe@geol.ku.dk

${ }^{3}$ Danish Coastal Authority per.soerensen@kyst.dk 
However the advance of the drained beach as compared to the control section was only 2 meters, so the authors concluded the local dewatering to be inefficient to trigger significant beach accumulation.

Passive drains: Another drain approach is Japanese, and is shown in figure 2. In this concept, a permeable layer is placed in the beach reaching from a high level in the upper part of the beach to a level below the lower part of the beach with connection to the sea. In this way the system utilizes the slope of the beach to create a pressure gradient (from high to low pressure) within the permeable layers, so no pumps are needed for the drainage (passive). Please note that the system in this case is connected to the seabed in order to ensure drainage.

A.

B.
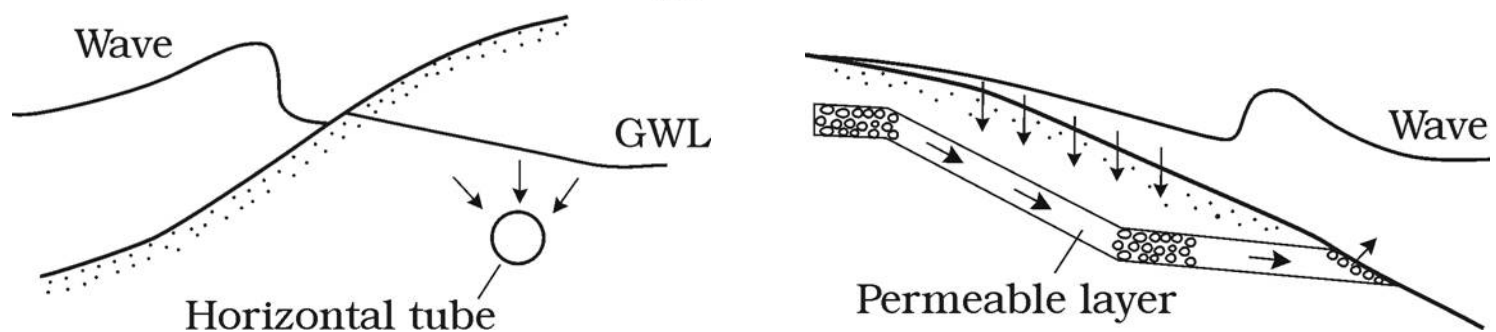

Figure 2. (A): The Danish "Beach Management System" drains the beach by pumping through nearly horizontal tubes located parallel to the shore close to the swash zone. (B) A Japanese system to drain beaches: here the tubes are replaced by a highly permeable layer, which is emptied by gravity. Please note the sea-connection of the permeable layer.

\section{Description of the PEM system.}

The PEM system belongs to the group of passive drains. The principle in the system is as follows: An array of vertical perforated tubes is drilled down in the beach sand. The total length of each tube is about $1.60 \mathrm{~m}$ with an inner diameter equal to $6 \mathrm{~cm}$. Slots are only present in the lower $80 \mathrm{~cm}$ of the tube. The slots are
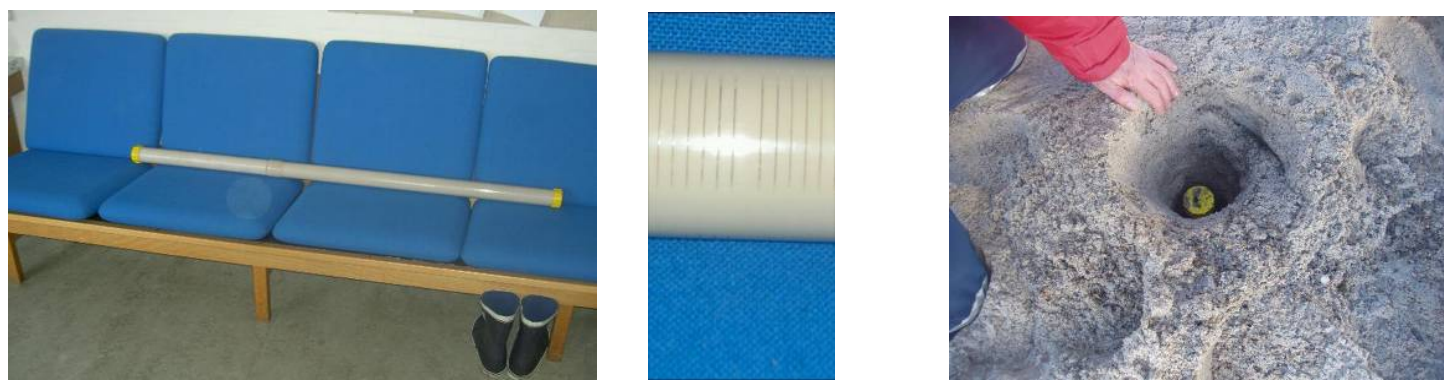

Figure 3. Photo of tube in full length, approximately $1.60 \mathrm{~m}$ long and with an inner diameter equal $6 \mathrm{~cm}$. The tube is without slots in the upper half, but it is ventilated at the top, so air can go through. Middle: Blow up of the tube: Slots of $0.2 \mathrm{~mm}$ width are cut in the lower half of the tubes, so water can flow in or out. Right: The tubes are initially buried, so the top is around $30 \mathrm{~cm}$ below beach surface.

only $0.2 \mathrm{~mm}$ wide in order to avoid penetration of sediment into the tube. The tubes are placed in rows perpendicular to the coastline. The distance between each tube in a row is 10 meter, and the distance in between the rows is 100 meters, see also fig 14. There is no explanation from SIC on how they obtained this configuration, but it corresponds to one tube per $1000 \mathrm{~m}^{2}$, which ensures a very cheap coastal protection. 


\section{Flow through the tubes.}

The flow in the beach can be introduced by the individual wind waves, by tide or storm surge or by supply of fresh water from the hinterland. The short periodic waves has not been considered to be a candidate, since the flow in the sand is so slow, that the in-and out flow of the tube in one wave period is negligible as compared to the amount of water transported to the beach during each wave run-up.

The fluid to be drained must be either water from the Sea (usually salty) or from inland (usually fresh). The flow must be either up- or downwards directed. If you have a flow in the tube, and it is upward, then the water must enter the tube at the bottom (or lower half) and escape at the top (upper half). If, on the other hand, the flow is downwards inside the tube, the opposite must be the case. For this reason it is surprising that the tube only is permeable in the lower part. Figure 4 shows an example on tidal-induced flow during falling tide.

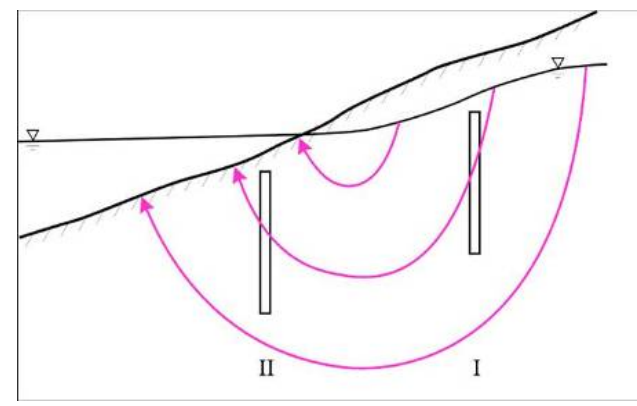

Figure 4. Schematic picture of tidal induced flow.

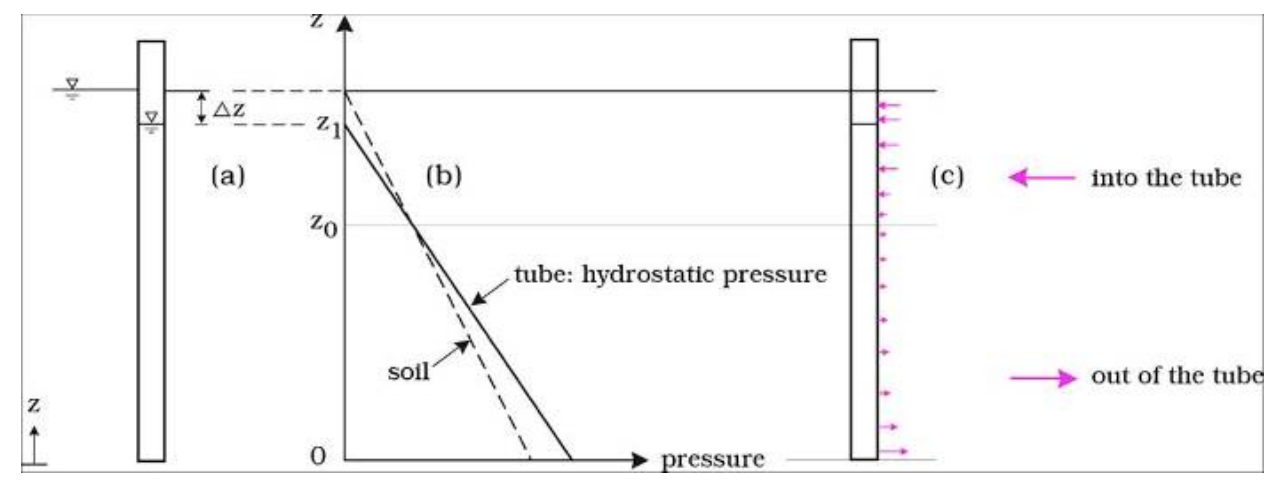

Figure 5: Schematic pressure distribution out-and inside the tubes.

At location I, the flow is directed down, and it is easier to flow through the tube than outside in the surrounding soil: in the tube there are nearly no flow resistance, and with small flow velocities, the pressure within the tube can be taken to be hydrostatic. In the soil you need an excess pressure gradient (in this case negative) to force the flow through the soil, where there is a considerable flow resistance (the Darcy law).

This is illustrated by the schematic pressure distribution in figure 5 . The continuity equation for the tube requires (in a quasi-steady flow) that the flow into the tube equals the flow out. This requirement determines the water level within the tube relative to the water level outside the tube. This difference is called $\Delta z$. In the upper part of the tube the water pressure in the soil is larger than the pressure in the tube. This will cause a flow into the tube. In the lower part of the tube, the conditions are opposite: here the 
pressure is largest within the tube, and there will be a flow form the tube to the soil. This shortcut through the tube of the near-tube flow will increase the vertical drainage. The question is: How much?

Let the permeability coefficient be $\mathrm{k}=0.005 \mathrm{~m} / \mathrm{sec}$, corresponding to $1 \mathrm{~mm}$ sand. Without the tubes a typical lowering-velocity of the water table in the beach due to tide (a drop of $1 \mathrm{~m}$ in 6 hours) will be $\mathrm{V}=$ $1 \mathrm{~m} / 6$ hours $=0.05 \mathrm{~mm} / \mathrm{sec}$. The hydraulic gradient $i$ to cause this flow is given by $i=\mathrm{V} / \mathrm{k}=0.01$. Over $2 \mathrm{~m}$ (the length of the tubes - this is actually exaggerated since there are only slots in the tubes in the lower 1 meter of the tubes) this corresponds to a loss in energy head $\Delta \mathrm{z}$ of $2 \mathrm{~m}$ multiplied by $i$, i.e. $\Delta \mathrm{z}=2 \mathrm{~cm}$.

The next question is how much water will flow through the tube if you have $\Delta \mathrm{z}=2 \mathrm{~cm}$ ? For this we did a simple experiment at DTU, where we installed the tube into sand as shown in figure 6 left, and looked at the flow through the tube. With a head drop of $\Delta \mathrm{z}=20 \mathrm{~cm}$, the flow is around $0.61 /$ minute (see figure 6 right), and for smaller head drops like $\Delta \mathrm{z}=2 \mathrm{~cm}$, the flow rate is around $\mathrm{q}=0.06 \mathrm{l} / \mathrm{minute}$. This corresponds to a flow velocity of $\mathrm{V}$ (tube) $=\mathrm{q} / \mathrm{area}=0.00006 \mathrm{cbm} /$ minute $/ 28 \mathrm{~cm}^{2}=0.35 \mathrm{~mm} / \mathrm{sec}$ or 7 times higher inside the tube than outside the tube for this specific case. In the table 1 below, the impact of different sand sizes in the beach for the drainage capacity of a tube is given. Lundgren et al suggest $\mathrm{k}$ to depend on $d_{10}(10 \%$ of the sediment is finer than this size, $\mathrm{d}$ given in $\mathrm{mm}$ ) by $\mathrm{k}=0.0125 \mathrm{~d}_{10}{ }^{2}$. This expression has been used in the table, all other parameters being the same as used above. For the flow through the tube, figure 6 is applied. Actually, when changing the sediment size, this experiment should be repeated with the corresponding sand size. In this case, the flow through the tube would be smaller for fine sediment, and larger for the coarse. Hence the drainage improvement would be smaller for the fine sand and larger for the coarse sediment.

Table 1 shows that the improved drainage of an area around each tube is only improved with less than 1 per thousand, even for a beach with a lot of fines. (Please note that $\Delta \mathrm{z}$ in case of fine sand becomes larger than the length of the tubes, which of course is not possible).

\begin{tabular}{llllll}
\hline $\begin{array}{l}d_{10} \\
\text { in }\end{array}$ & $\mathrm{k}$ in $(\mathrm{m} / \mathrm{s})$ & $\begin{array}{l}\text { Hydraulic } \\
\text { gradient } i\end{array}$ & $\Delta \mathrm{z}$ in $\mathrm{m}$ & $\begin{array}{l}\mathrm{V}(\text { tube }) \text { in } \\
\mathrm{mm} / \mathrm{s}\end{array}$ & $\begin{array}{l}\text { Improved } \\
\text { drainage in 1 } \\
\text { per thousand }\end{array}$ \\
$\mathrm{mm}$ & & & & & 0.65 \\
0.05 & $3.75 \mathrm{E}(-5)$ & 1.33 & 2.66 & 6.5 & 0.16 \\
0.1 & $1.5 \mathrm{E}(-5)$ & 0.33 & 0.66 & 1.6 & 0.04 \\
0.2 & $6 \mathrm{E}(-5)$ & 0.083 & 0.17 & 0.41 & 0.01 \\
0.4 & $4.68 \mathrm{E}(-4)$ & 0.0208 & 0.042 & 0.103 & 0.0025 \\
0.8 & $1.17 \mathrm{E}(-4)$ & 0.0052 & 0.0104 & 0.0256 & \\
\hline
\end{tabular}

Table1 Improved drainage capacity of tidal flow in $10 \mathrm{~m}$ width along the beach due to the tubes placed in homogenous soil.
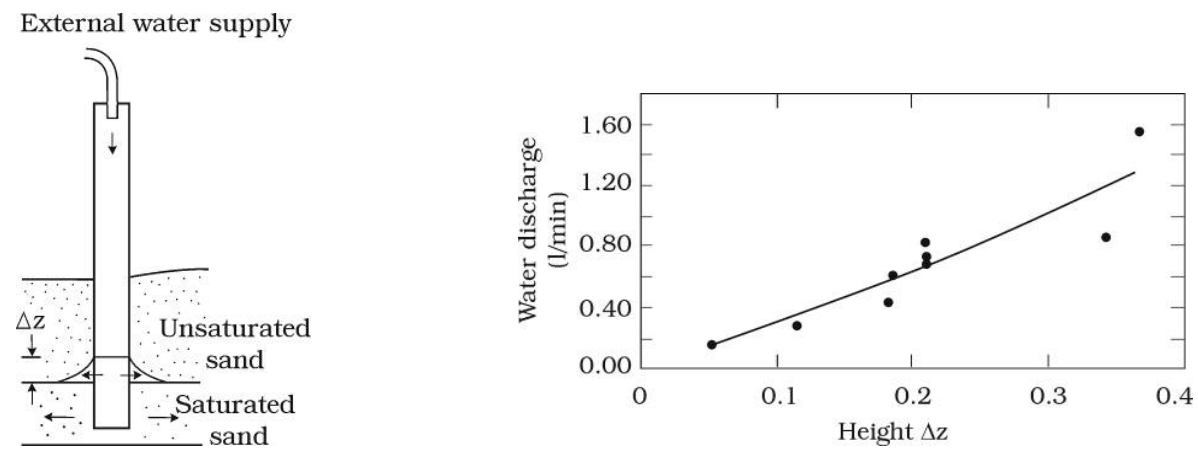

Figure 6. Set-up to determine the flow through the tube. The sand size in the experiment is about $0.4 \mathrm{~mm}$.

\section{What happens if you have permeable or impermeable layers?}

SIC claims that the improved drainage effect to a large extent stems from presence of permeable/nonpermeable layers. In the following the expected impact from the PEM-tubes is discussed regarding different 
combinations of soil properties. For simplicity only one tube is shown in the beach, and we are considering the case of a falling water table in the beach.

\subsection{The in-homogeneous beach: presence of permeable layers.}

Figure 7 shows the basic case, where the water will locally easier flow through the pipe, so you get a faster velocity from $A$ to $B$, but the water still needs to flow from $B$ to $C$, and there is no trigger for this, so not much has been gained by installing the tube, it is nearly just as easy to flow from $\mathrm{A}$ to $\mathrm{C}$ as from $\mathrm{B}$ to $\mathrm{C}$.

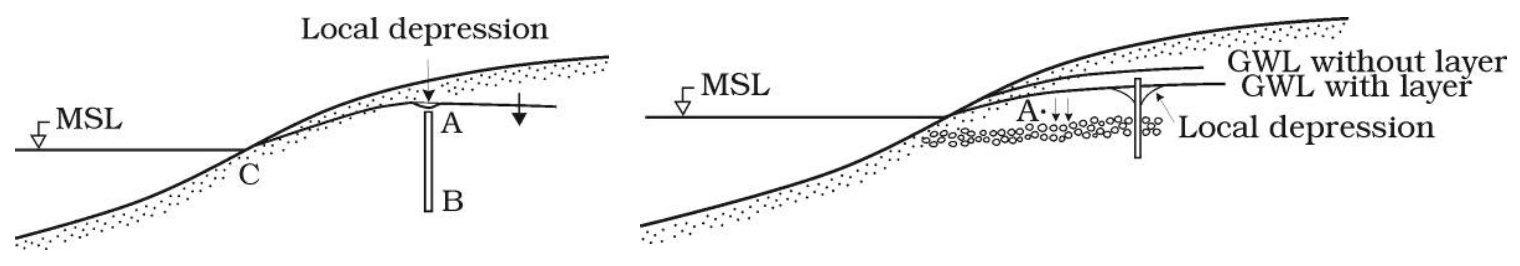

Figure 7. Left: The drain will locally make a depression cone around the tube. However, the size of the cone is likely extremely small, and most of the beach water will flow directly rather than through the tube towards the sea. Right: The presence of a sea-connected permeable layer will anyway- with or without tubes - improve the drainage of the beach. Sea-connected permeable layers will only have a local effect, because most of the water flows directly to the permeable layers.

"Activation of Permeable layers": Figure 8 suggests that a trigger for the flow from B to C can be established by the presence of a isolated permeable layer. As sketched in figure 8 , the tubes can act as a

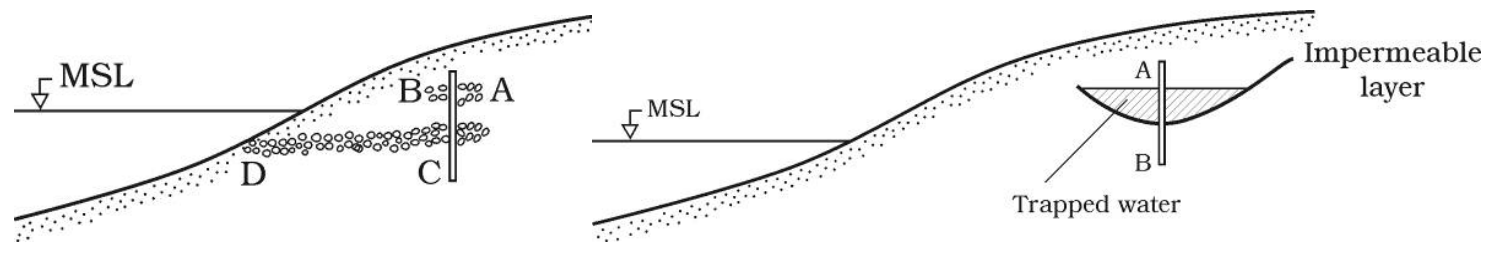

Figure 8. Left: The upper layer A-B will be drained better to the sea-connected layer CD by a vertical drain; Right: water trapped in a convex shaped bowl formed by the inhomogeneous layers may escape through the tubes. The effect will anyway only be very local.

vertical link in between the different permeable layers. At least it will mitigate the flow from A to C, so there will be an improvement if this interconnection continues right to the sea, i.e. CD exists. If the interconnection does not exist, the flow through the tubes will still be very slow.

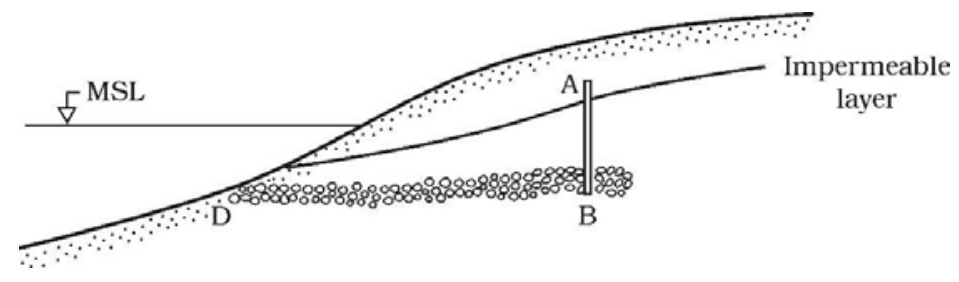

Figure 9. A drain located in a Sea-connected high-permeable layer, and penetrating an impermeable layer above the permeable layer will improve the drainage above the impermeable layer. This will require a very special configuration in the beach. 


\subsection{The in-homogeneous beach: presence of impermeable layers.}

Next we consider the presence of impermeable layers, formed be nearly horizontal layers of clay or other fines mixed with the sand. The authors can identify two cases, where a vertical drain may have some positive impact, see figure 8 (right) and figure 9.

\subsection{Refined modeling:}

In order to test some of the considerations outlined above, it was decided to apply a numerical physicalbased model for the groundwater flow to test how much water will flow through a PEM. Salt water flow was included, because SIC claims that an effect of PEM is to relieve the fresh water pressure from a wedge, formed by supply of fresh water from the hinterland. The modeling is done by a $2 \mathrm{D}$ model, corresponding to that the longshore distance of the PEMs is zero. In the real world the distance is 100 meter, and a PEM only occupies $6 \mathrm{~cm}$ pr 100 meter. However, the model still is useful for estimating the velocities through the PEMs.

The effects of tides on groundwater flow and salt transport were therefore simulated in an idealized crosssection using Feflow (Diersch, 2006). The two-dimensional conceptual model was developed to reflect the hydrogeological and tidal conditions at the West coast of Denmark. The model accounts for variablysaturated flow with density-dependent flow and salt transport. The model region is $100 \mathrm{~m}$ long with a sloping beach face from $-2 \mathrm{~m}$ to $+2 \mathrm{~m}$. The lower boundary located at $-10 \mathrm{~m}$ was assumed impermeable. Freshwater flow discharges to the beach at the inland boundary. The tidal amplitude was $0.5 \mathrm{~m}$.
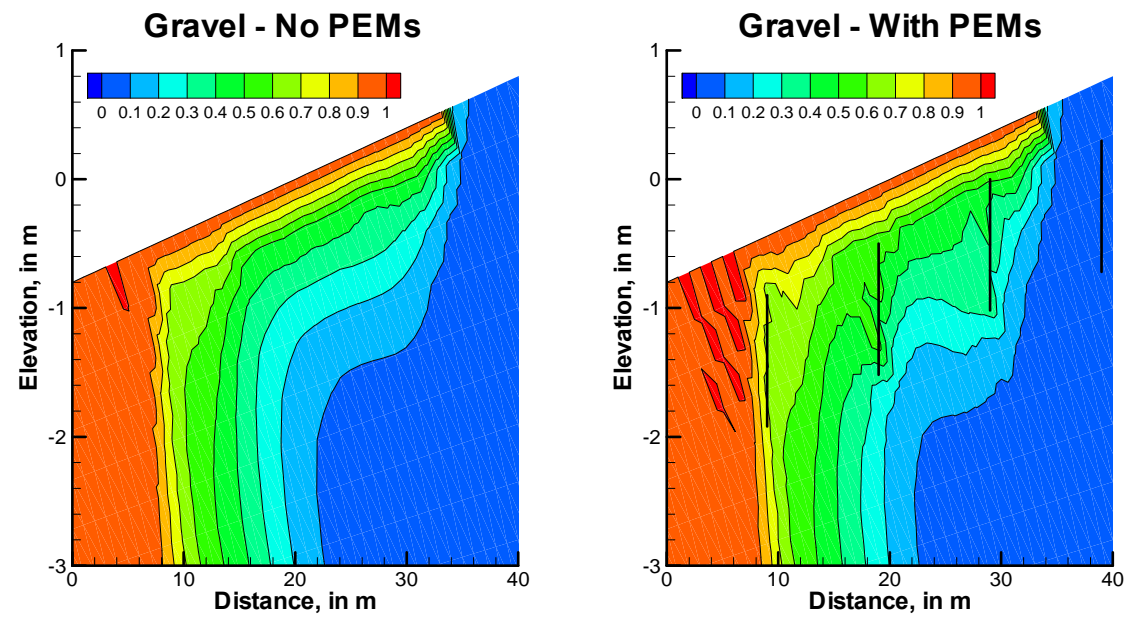

Figure 10. Example simulation of a system with a gravel layer, without PEMs (left) and with PEMs (right). The PEMs are indicated as vertical lines. The simulation is shown at high tide. Only a small window of the simulation region near the tidal zone is shown.

Figure 10 shows the salt distribution near the tidal zone for the system with a gravel layer placed approximately $1 \mathrm{~m}$ below the sea bed near the mean sea level, and with no PEMs installed and with PEMs installed. The salt water intrusion is shown at high tide. The draining effect of the gravel layer can better be shown at lower tides. For example, Figure 11 (left) shows the same system at mean sea level. The draining effect of the gravel layer is obvious from Figure 11 (left, A), i.e., freshwater flow from the hinterland is primarily discharged to the sea through the gravel layer. The velocity distribution is difficult to show for a system with PEMs because of the much higher velocities in the PEMs than in the porous medium, Figure 11 (right). From Figure 10 it is clear, that the PEMs have a small local effect on the saltwater distribution near the slotted part of the PEMs, in fact, they also transport more saltwater into the system (during high tide). Several scenarios were simulated with a freshwater inflow (low, medium, high) from the hinterland, all with and without PEMs, and with and without gravel layers. The slotted part of the PEMs were simulated as pipes with a much higher hydraulic conductivity than the porous medium and were placed in the beach approximately according to how real PEMs are installed. 

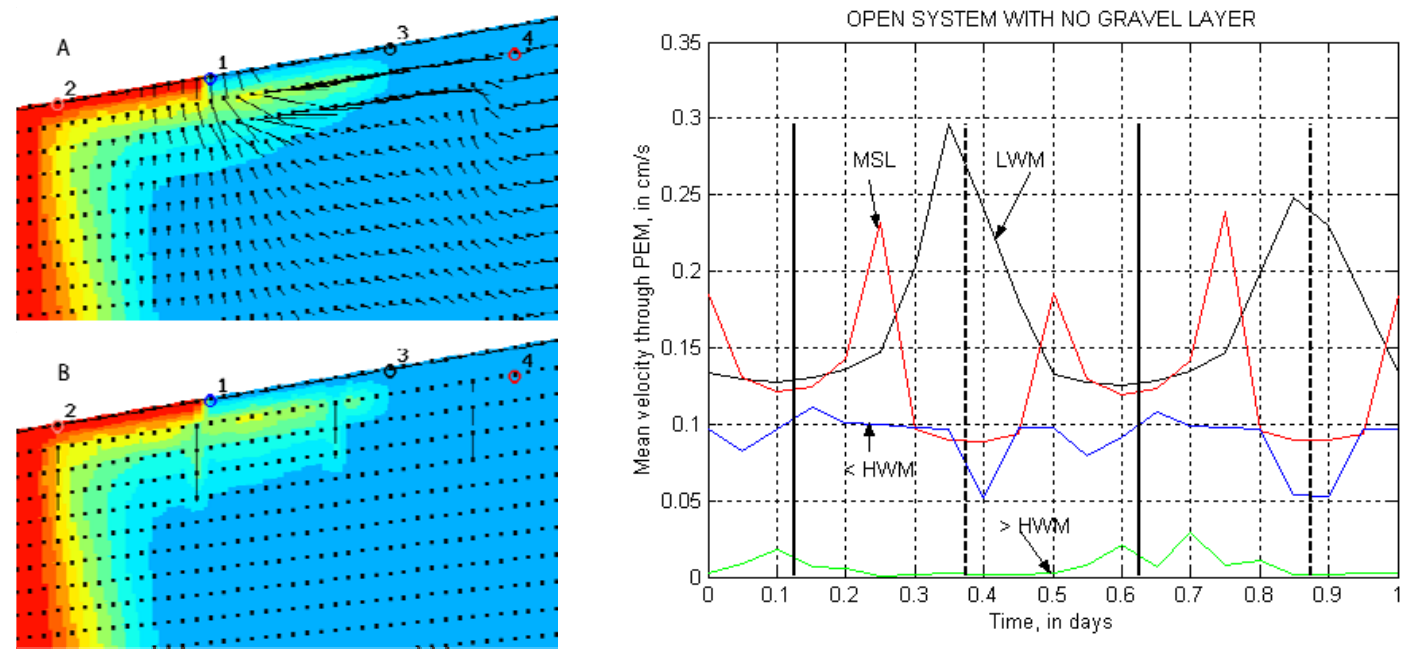

Figure 11. Left: Example on simulation of a system with a gravel layer, without PEMs (A) and with PEMs (B). In B the PEMs are indicated as vertical lines (actually showing high velocities). The salt concentration is shown with red color equal to sea water and blue equal to freshwater. Points 1, 2, and 3 are mean sea level, low tide level, and high tide level, respectively. The distance between points is approximately $10 \mathrm{~m}$. Right: Simulated velocities at the mid-point of the four PEMs over a tidal cycle. High and low tides are indicated with vertical solid and dashed lines, respectively. $d_{10}$ is about $0.17 \mathrm{~mm}$.

gravel layer or penetrate a lower-permeable (clay) layer were also investigated. Finally, the effects of having a gravel layer connect to the sea or not were evaluated.

Figure 10 shows an example simulation (shown at mean sea level) of a system with a gravel layer approximately $1 \mathrm{~m}$ below the sea bed near the mean sea level; without PEMs (A) and with PEMs (B) (the velocity distribution is difficult to show for a system with PEMs because of the much higher velocities in the PEMs than in the porous medium). The draining effect of the gravel layer is obvious from Figure $10 \mathrm{~A}$, i.e., freshwater flow from the hinterland is primarily discharged to the sea through the gravel layer.

Figure 11 left shows the tidal changes in the velocities at the mid-point of the four PEMs for the case without a gravel layer. There are peak flows of up to $0.2-0.3 \mathrm{~cm} / \mathrm{s}$ in the two PEMs closest to the sea, whereas the two other PEMs located above the MSL is much more inactive likely because the water table was found to drop below the PEMs during low tides. It is also apparent that the two most active PEMs have peak flows at different times during the tidal cycle. At low tide it is the PEM near the LSL that is most active, and, vice versa, at high tide it is the PEM near the HSL (but below) that is most active.

In summary, the sequence of simulations indicated that the effects of the PEM system are generally small when compared with the integrated outward or inward fluxes across the sea bed during a tidal cycle. In the base case the extra outflow caused by the PEMs is on the order of 5\%. Also, it was found that the effects of changing the hydrogeological conditions (gravel/silt/clay layer, freshwater inflow) have a larger impact on inflow and outflows across the beach than having PEMs or not.

\section{The Morphodynamic fingerprint.}

It was decided by the Danish Ministry of Transportation that a full scale experiment should be performed at the very exposed Danish West coast to verify the usefulness of the tubes. The littoral drift here is 2.2 mill. $\mathrm{m}^{3}$ towards south, and alongshore undulations can be observed on the coast. An 11 kilometer long stretch was allocated to the test. At the northern part of the test site, the coast is nourished on the outer bar, approximately 500-700.000 cbm per year. 


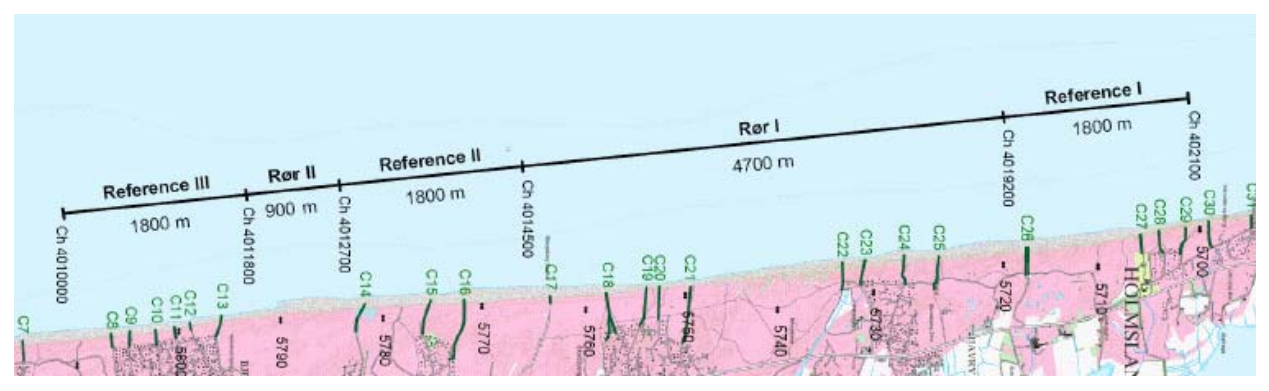

Figure 12: The splitting up of the test site in regions with tubes (rør) and no tubes (reference)
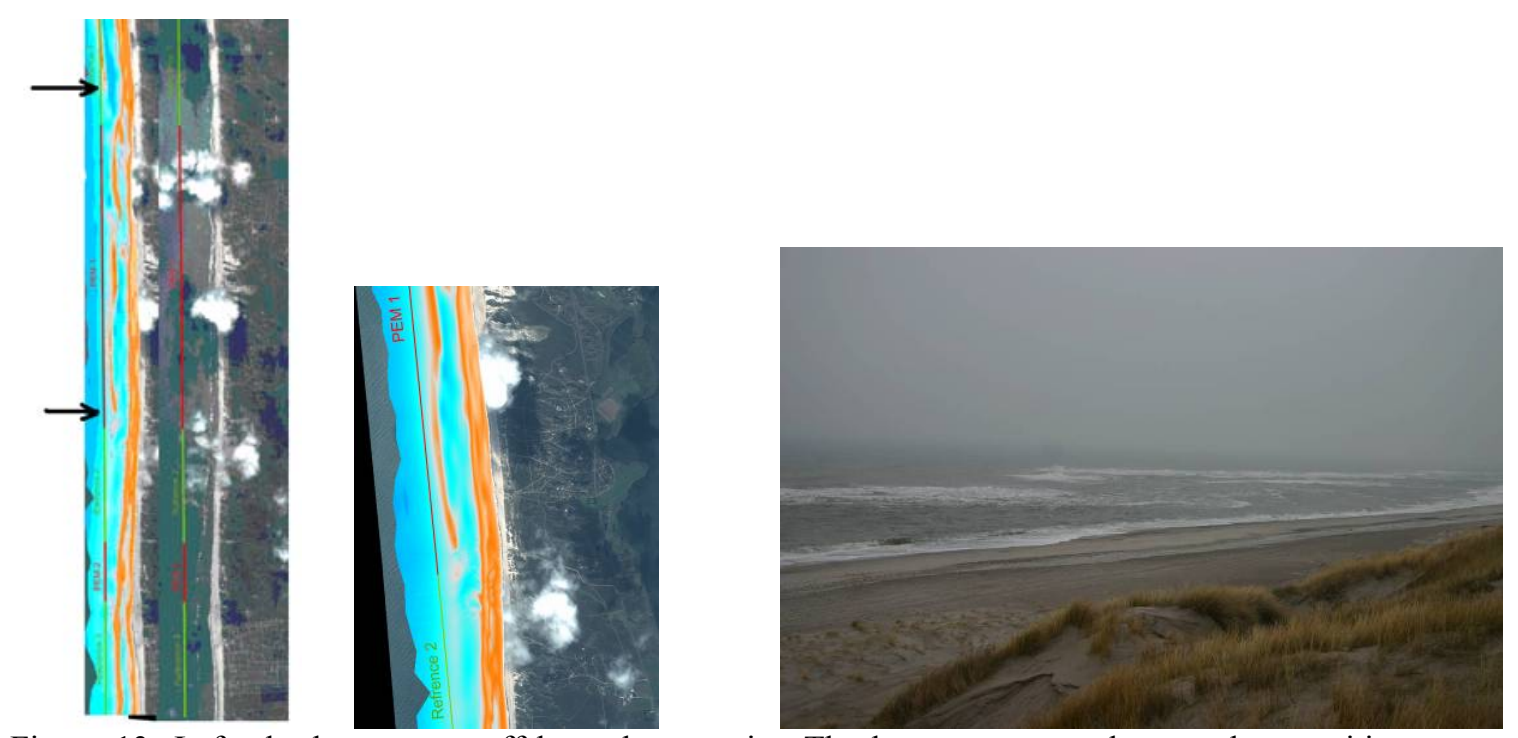

Figure 13: Left: the bar system offshore the test site. The bars stop very close to the transition zones. Middle: Detailed survey of the bathymetry in the transition region between Rør 1 and Ref 2, summer 2007. Right: the presence of rips in bars visualized by the breaking wave pattern.

While it usually is easy to explain why a devise works, it is certainly much more difficult to verify that it doesn't work. The exercise here is to prove it from the morphodynamic fingerprint. The stretch was divided in 2 sections with tubes: a 4500 meter long section and another much shorter (900 meter). Three Reference sections, each 1800 meters long, are sections without tubes, for comparison. The changes in beach and shore face volume were measured during all three years.

\subsection{The near tube fingerprint.}

It cannot be observed, that sand is collected in the neighborhood of each tube. Maybe because the tubes are buried so deep in the beach that it can't be felt at the beach surface: you actually only have an one meter long active part with slots buried more than one meter below beach surface, so the radius in the local sink in the water table will be increased by some meters. However, the drain must form a local sink of the water table to work, so since no local accumulation occurs around the individual tubes, at least collection of sand must take place around the individual arrays if the tubes shall have any function.

For instance during the first 3 month period, the beach in rør 1 in average gained volume of 25-30 $\mathrm{cbm} / \mathrm{m}$ : If this increase in beach volume is due to the tubes, each tube row collect $25 \mathrm{cbm}$ per meter 
multiplied by $100 \mathrm{~m}$ (the distance between the rows) or $2500 \mathrm{cbm}$. How can you collect so much sand without visually to be able observing local accretion around each row??

\subsection{The test site.}

Because the impact from the tubes is such, that you can not observe accumulation locally around the tubes, the test became more a kind of a "box-study", where changes in beach and dune levels were measured over longer distances along the beach. We are after an impact which can not be identified around each array, but on the other hand side it is expected to be so distinct, that the tube-impact does not spread too much into the reference sections with no tubes. The measured profile was divided in four fixed boxes (Eulerian approach): the dunes, the beach, offshore 1 (from the coastline and 300 meters offshore) and offshore 2: the next 300 meters, see figure 14. Only the beach-results are presented in this paper. The "beach-box" is a measure of the volume from the initial dune foot $(+4 \mathrm{~m})$ and 100 meter in the offshore direction(so sometime the outer part of this is in the water, and in the worst case scenario the inner bar can be a part of the "Beach box"). The reason for this definition was to "measure the erosion-deposition where the tubes were". All measurements on land were performed with alongshore intervals equal 100 meters, while the interval offshore was 200 meters.

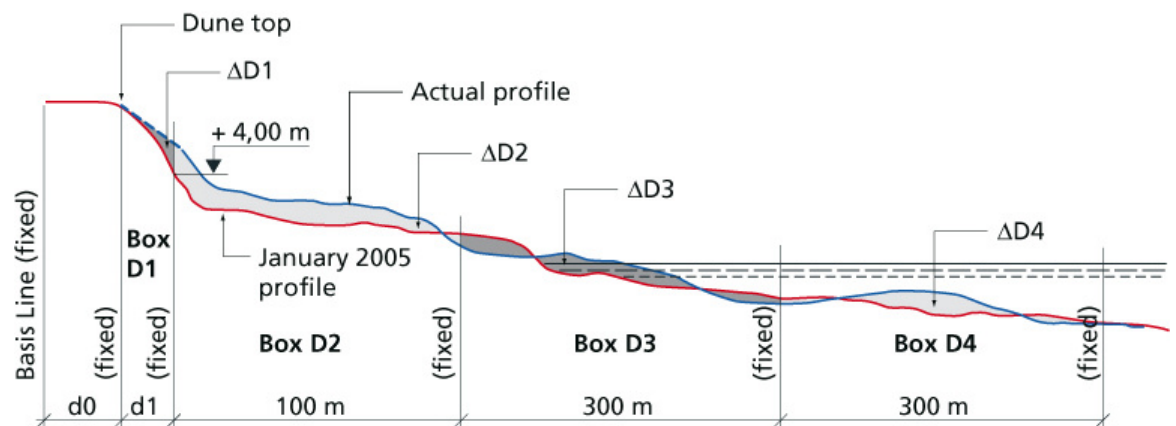

Figure 14: Definition of the different boxes, in which a cross section was divided.

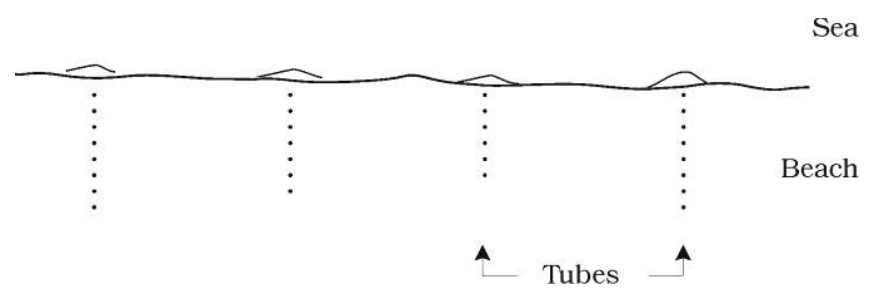

Figure 15: No individual salient are observed in front of the tube-rows after installation, like no local accumulation are observed on the beach, see figure 16 (left).

\section{Results}

\subsection{Correlation between tubes and accretion on spatial scales of the size like the individual reaches.}

Along the test stretch you have a sometimes erosion, and sometimes deposition. You can then ask whether there is a correlation between deposition and the tube covered regions and visa versa. If there is a correlation, this could be an indication of a positive impact of the tubes. Table 2 lists the average values after 3 years on each individual stretch., while table 3 shows the accumulated variation over all three years. 

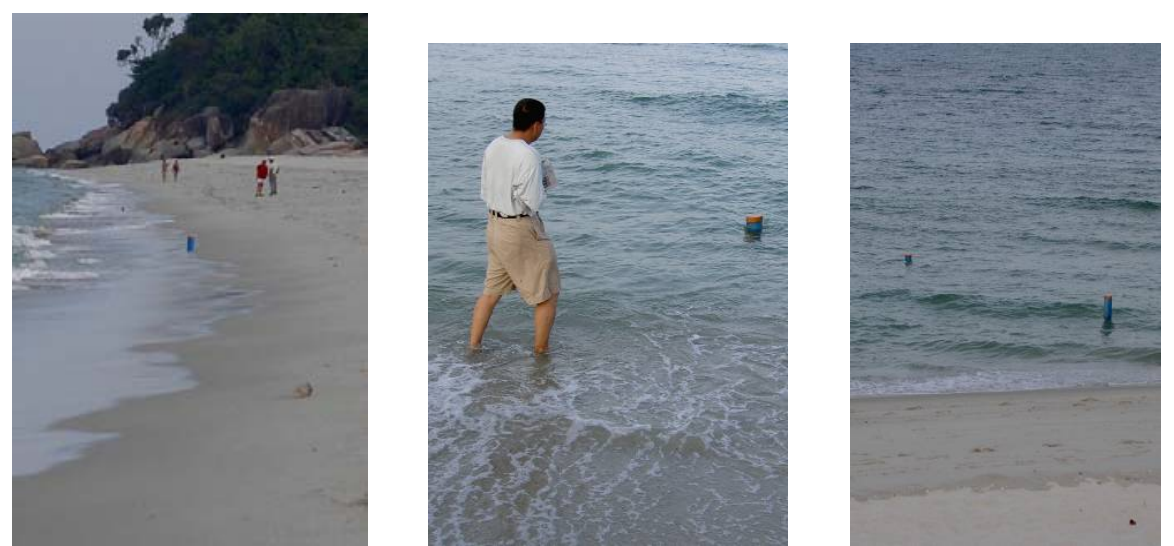

Figure 16: In Malaysia in front of the Hyatt Kuantan Hotel, some tubes are now located offshore, but the Malaysian authorities are still happy with the system.

You have a gain in the beach in refl and a loss in the dunes in ref1, which is in favor and the opposite for the tubes regarding refl, and you have exactly the same thing in rør 2, so here the beach is in disfavor and the dunes in favor of the tubes.

Finally, the important very long rør1 simply ends up with a zero regarding the beach, and a small plus regarding the dunes.

\begin{tabular}{l|ccccc}
\hline & Reference 1 & Rør 1 & Reference 2 & Rør 2 & Reference 3 \\
\hline Dune box: (D1) & 12 & 11 & -40 & 14 & 1 \\
Beach box: (D2) & -36 & 0 & -164 & -26 & 114 \\
\hline Beach+dune & -24 & 11 & -204 & -12 & 115 \\
\hline
\end{tabular}

Table 2. Changes in volume $\mathrm{cbm} / \mathrm{m}$ after three years.

\subsubsection{Yearly temporal variations.}

The variation in beach volume in the large tube-covered region is plotted in figure 17: The volume in rør 1 (the full drawn line) shows a strong fluctuating signal over the year, so the final answer regarding the test simply depends on the cut in time: you get two different conclusions whether you stop the test three month earlier or later. This is typical for a process with big fluctuations: you need a lot of time to find a weak trend (like the global temperature increase in the atmosphere: you cannot detect it in months or a few years, you need decades of years).

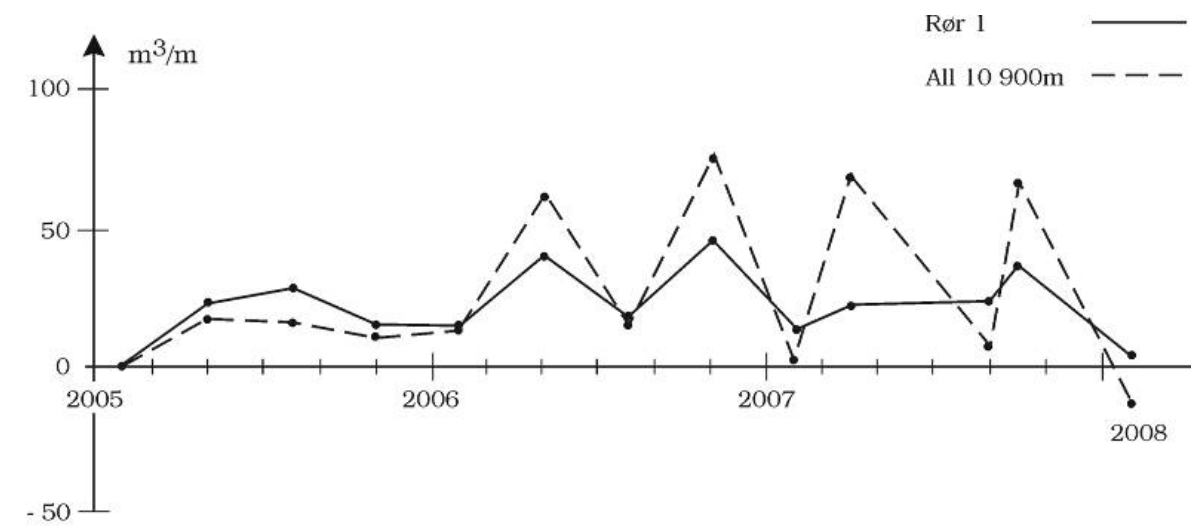

Figure 17: Temporal Variation in beach volume: The beach volume changes so much that the conclusion depends on the cut of the test. Sep 2007: $+35 \mathrm{cbm} / \mathrm{m}$ in front of rør1, Jan 08: $0 \mathrm{cbm} / \mathrm{m}$. On the total test stretch (dashed line in the figure) you have in average Sep 07: $+67 \mathrm{cbm} / \mathrm{m}$ and Jan 08: $-15 \mathrm{cbm} / \mathrm{m}$. The values are positive because the test began just after the big storm January $8^{\text {th }}$ and $9^{\text {th }} 2005$. 


\section{2: Observed trends in the transition zones:}

The next step will be to go into further details (not as detailed as to the near-tube morphology as described in section 5.1), namely to consider the detailed transition between the different stretches.

Figure 15 shows the alongshore variation in beach volume at the beginning and at the end of the test. Each bar represents a measurement with a longshore interval of $100 \mathrm{~m}$.

Actually something happens in the neighborhood of the transition zones as discussed below.

\subsubsection{The breach in the transition between rør 1 and ref 2 .}

The most striking feature at all along the site is the breach in the dunes in the neighborhood of the transition between rør 1 and ref 2 . Here, the beach becomes weaker over a wider and wider distance during the test. It could be a proof of a positive impact from the tubes, since the erosion develops at the transition location from a tube covered area to a no-tube area. Figure 18A shows that the transition between tubes and no tubes is placed exactly where the beach had minimum volume.

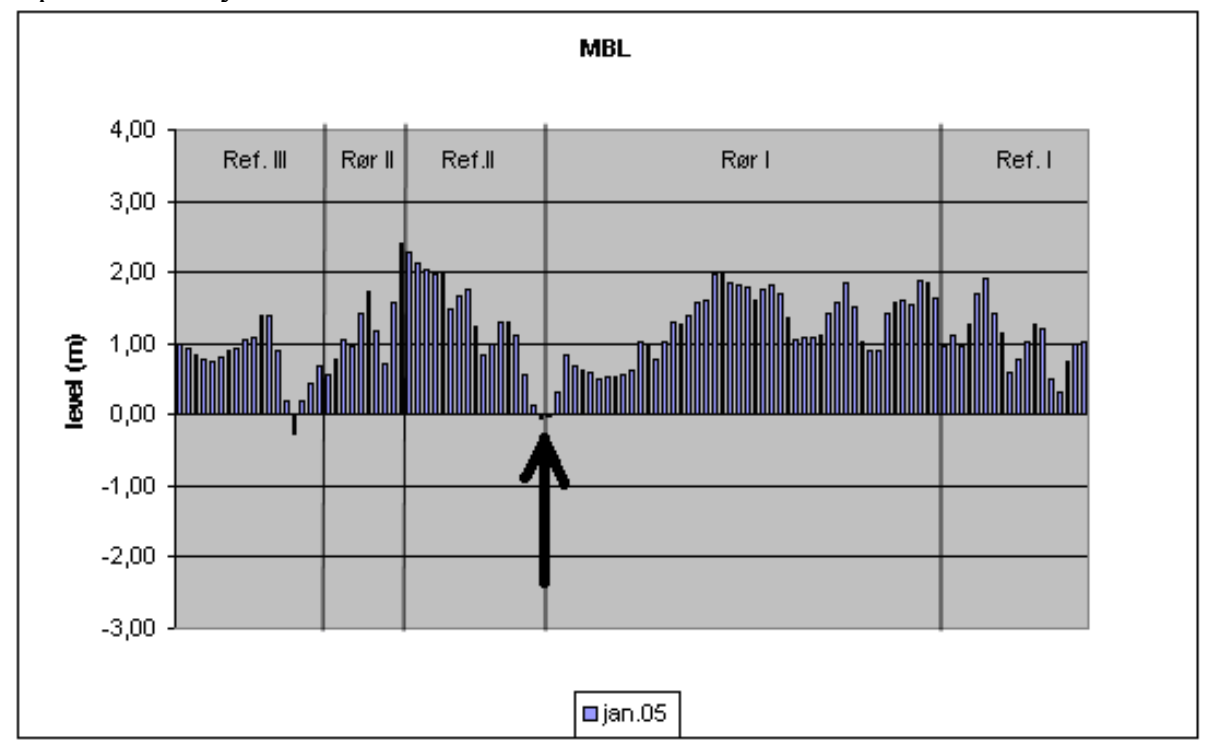

Figure 18A: Mean Beach level at the start of the experiment. The beach was weak at the transition from the very beginning.

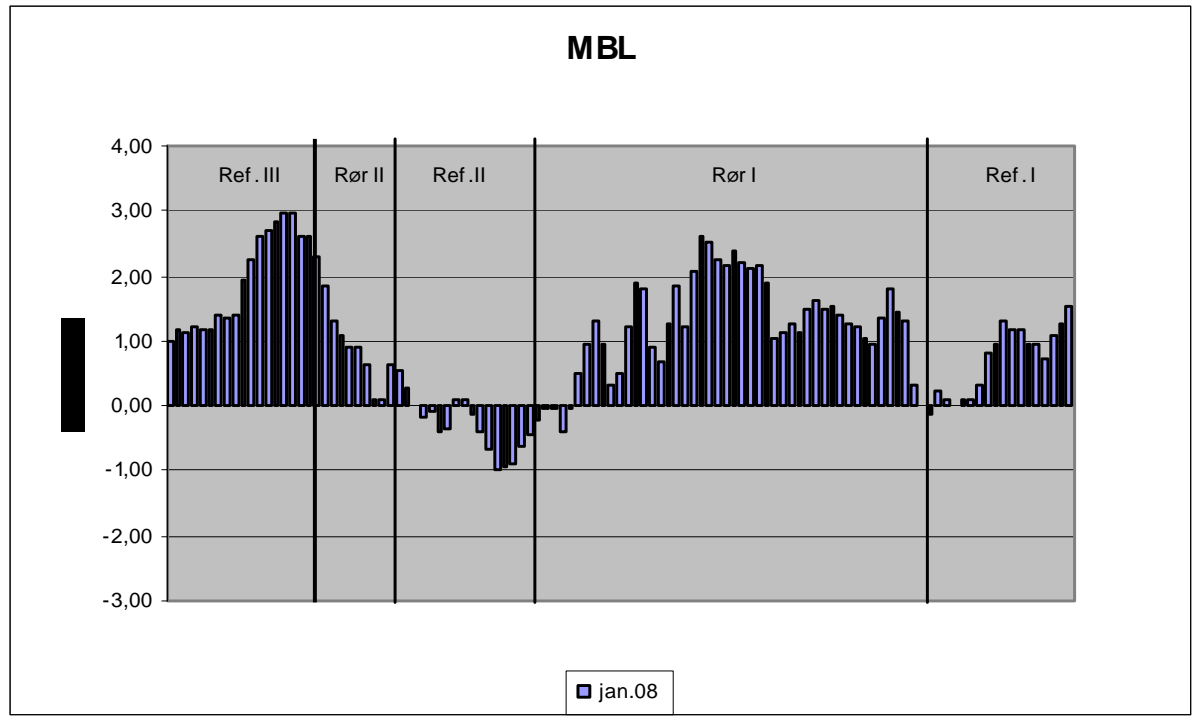


Figure 18B: Final beach level.

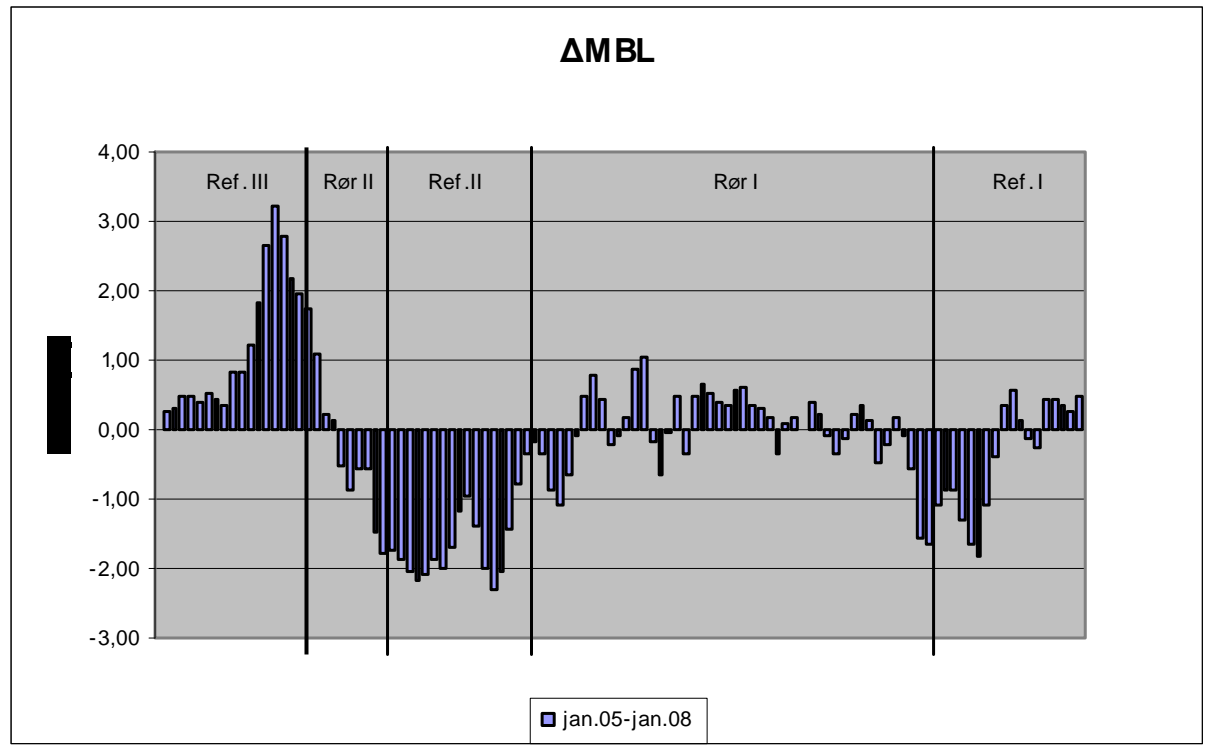

Figure 18C: Changes in mean beach level during three years.

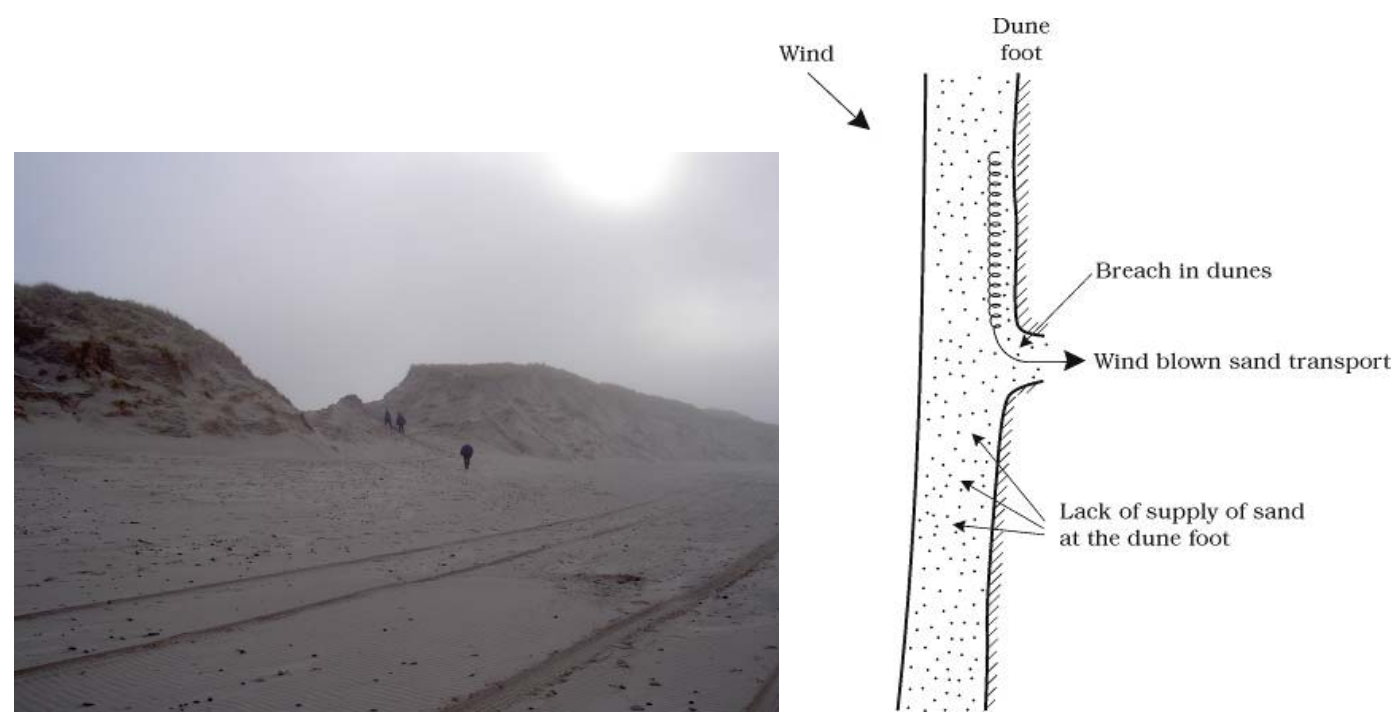

Figure 19. A breach will accelerate the wind born sediment transport through the dune system and will result in a lack of sediment downwind the breach. When the breach matures, the foot downwind will be reestablished.

The bottom bathymetry in front of the coast is known to have a major impact on the beach: breaker bars in front of the beach protect the beach, resulting in less wave action further onshore. A hole or a break in the bar on the other hand side allows the waves to propagate through this hole without breaking, resulting in larger wave action closer to the shore.

The bar-behavior in the entire region is quite complicated, and probably also affected by the large nourishment on the bar just north of ref 1 . With respect to the site under investigation - the transition 
between rør 1 and ref 2 - it is clearly seen from figure 13 that the outer bar located around 3-400 meter offshore terminates just updrift the location, where the beach becomes narrow.

This termination of the bar implies, that waves can penetrate further onshore without breaking (on the bar), thus causes the locally weaker beach, see the sketch figure 20 (left). The photo in figure 13 shows the impact on the waves from the termination of the outer bar at the location under consideration, so the termination can actually be observed visually without viewing the seabed.

When the outer bar disappear, a redistribution of the long shore sediment transport will occur: as long as the outer bar is present, the high waves will break here, generating a long shore current and associated long shore sediment transport on this bar. When the bar is no longer present, the high waves will break closer to the shore, and thereby increase the sediment transport closer to the beach. This local increase in near long shore sediment transport capacity results in a local erosion of the beach (figure 20 (left)).

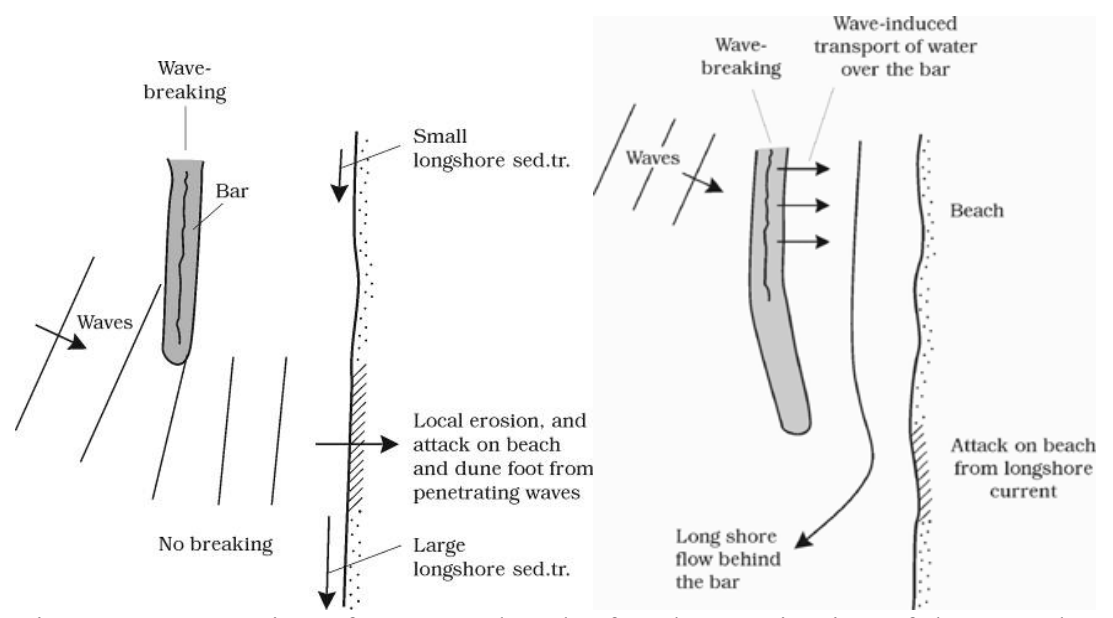

Figure 20: Formation of a narrow beach after the termination of the outer bar. Left: Increased wave attack. .Because the waves are spread by diffraction, they might propagate right into the swash zone. Right: concentration of the long shore current behind a crescendic long shore bar (originally suggested by Søren Knudsen, KDI).

The dune also loss significant volume as illustrated in fig.21: erosion is not observed before October 06,

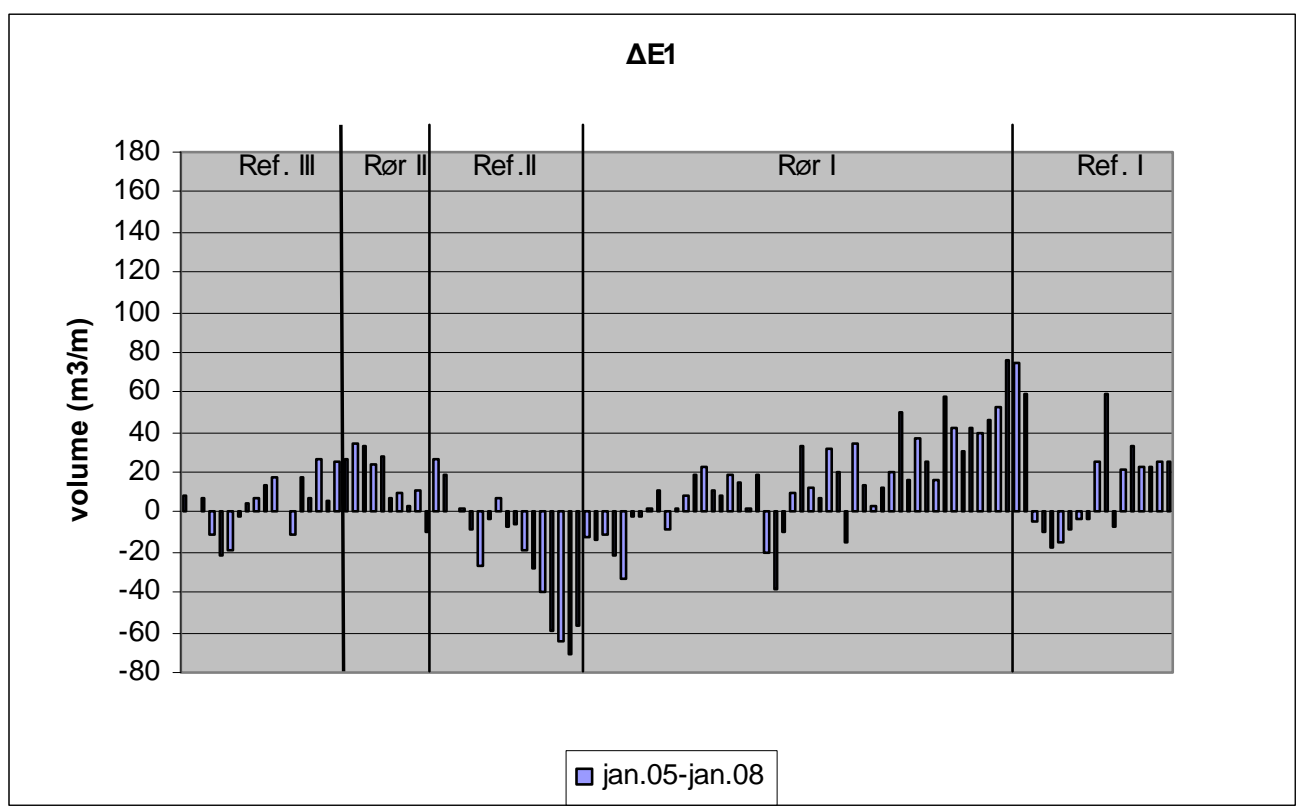

Figure 21: loss in dune volume through the three years. ( $\Delta \mathrm{E} 1$ corresponds nearly to $\Delta \mathrm{D} 1$ in figure 14$)$. 
i.e. with a significant delay as compared to the erosion in the beach. From January 07 the erosion caused a real breach in the dune system 40 meter wide. The process is most likely that the narrow beach allows attack on the vegetation of the dune foot during the storms late 2006, and with a destroyed vegetation, the wind can easier attack remove the dune sand. The erosion will most likely stop when the beach again becomes wider.
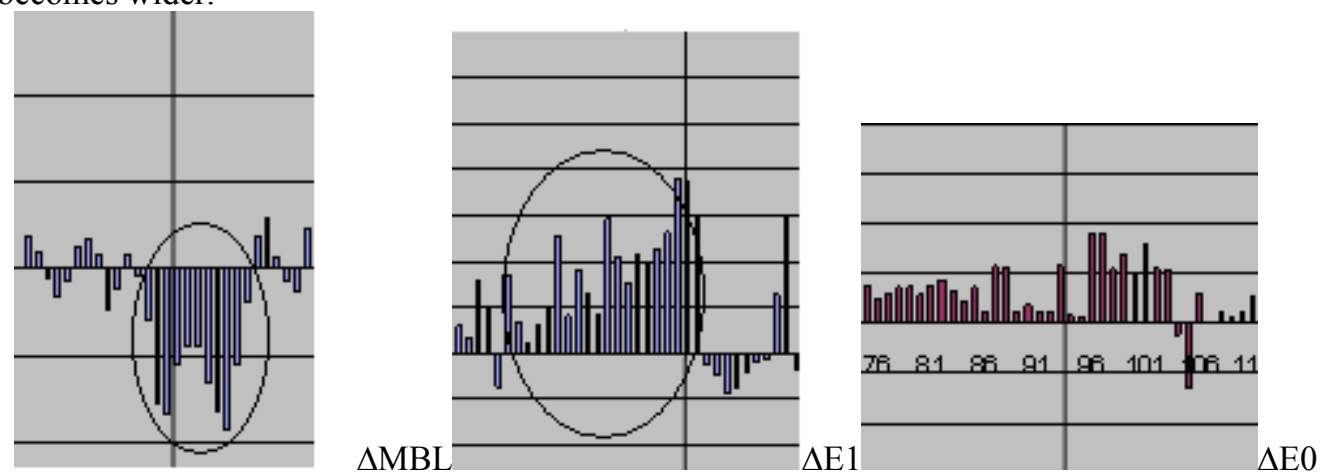

Figure 22. Changes close to ref1-rør1 in volume during the three years testing in beach, dune slope and dune top. The local Gain in dunes in rør1: approx $5000 \mathrm{cbm}$ in three years. The local loss in beach: approx $15000 \mathrm{cbm}$ in three years.

\subsubsection{The increase in dune volume in the upper part of rør1.}

It is very dubious whether the tubes can have any impact on the dunes. You might arguer that if the tubes collect more sand at the beach, then you have more sand which can be blown by the wind up into the dunes. In the transition between ref 1 and rørl you observe an increase in dune volume, in total about $5000 \mathrm{cbm}$ as encircled in figure 20 (middle). The increase in the dune volume do not begin exactly at the transition, but $300 \mathrm{~m}$ updrift. At the first 400 meters of rørl you get a similar loss in the beach, so here you might have a transport of sand from beach to dunes. The total loss in the beach shown in the circle figure 20 left is about 15000 cubic meters, of which about $4000 \mathrm{cbm}$ occurs in rør1. Should it be related to the tubes you should have no loss here in the beach. Further south in rør 1 you still have a certain accumulation in the dunes and no loss in the beach (say: 400 to 1400 meter down into rør1), so in total you here have accumulation. This is most likely due to the characteristics of windblown sand, which can deposit further downwind of where it is eroded, if you find a suitable dune bathymetry, where settling can take place.

However, it is striking that you get a sudden increase in the accumulation of sand in the dune, and this is difficult to explain. Several factors might contribute to the deposition: a sudden increase in beach width by about $40 \%$ at exact the same location gives the wind a wider area from which it can sweep sand to the dunefoot, - a certain correlation between beach width and dune accumulation is proved to occur in the test region, so accumulation is to be expected in the dunes. Also a smaller breach located just updrift the transition can supply a lot of sand. But the main reason is probably the bathymetry at the dunefoot, which is suitable for trapping sediment, see the photo figure 23.

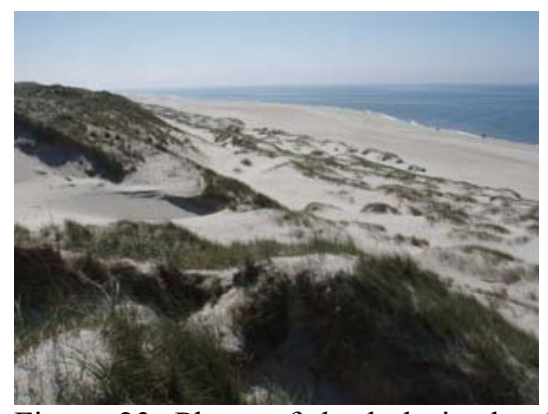

Figure 23. Photo of the hole in the dunes just in the transition between refl and rør 2, May 2008. The Figure also shows, that there is a room for sedimentation upstairs the dune foot. 


\begin{tabular}{l|rrrrrrrrrrrr}
\hline & $\mathbf{0 4 . 0 5}$ & $\mathbf{0 7 . 0 5}$ & $\mathbf{1 0 . 0 5}$ & $\mathbf{0 1 . 0 6}$ & $\mathbf{0 4 . 0 6}$ & $\mathbf{0 7 . 0 6}$ & $\mathbf{1 0 . 0 6}$ & $\mathbf{0 1 . 0 7}$ & $\mathbf{0 3 . 0 7}$ & $\mathbf{0 8 . 0 7}$ & $\mathbf{0 9 . 0 7}$ & $\mathbf{0 1 . 0 8}$ \\
\hline Ref. I & 13 & 3 & -12 & -11 & -7 & -18 & & -32 & 24 & -13 & 38 & -36 \\
Rør I & 22 & 29 & 17 & 17 & 40 & 19 & 43 & 11 & 21 & 21 & 35 & 0 \\
Ref. II & -10 & -32 & -42 & -55 & -41 & -65 & & -105 & & -150 & & -164 \\
Rør II & 45 & 58 & 68 & 93 & 92 & 87 & 100 & 38 & 185 & 27 & 207 & -26 \\
Ref. III & 25 & 29 & 38 & 54 & 93 & 82 & 118 & 104 & 188 & 113 & 139 & 115 \\
\hline Average & 19 & 18 & 11 & 14 & 60 & 16 & 74 & 4 & 68 & 5 & 67 & -15 \\
\hline
\end{tabular}

Table 3. Cumulative changes in the beach volume D2 $(\Delta \mathrm{D} 2)$ from 01.05 (January 2005). The last line is the average over all 10900 meters

\begin{tabular}{l|rcrrr}
\hline & Ref. 1 & Rør 1 & Ref. 2 & Rør 2 & Ref. 3 \\
\hline Dune box: (D1) & - & + & + & + & 0 \\
Beach box: (D2) & + & 0 & + & - & - \\
Inner Offshore box: (D3) & + & - & - & + & - \\
\hline Outer Offshore box: (D4) & - & - & + & - & - \\
\hline
\end{tabular}

Table 4. Overall changes in the different sections over all three years: + means accretion in rør, or erosion in ref, and vice versa, so + is in favor of the tubes.

\section{Summary:}

Near tube flow: Nearly no driving forces exist to activate the flow near the tubes. A simple estimate of the impact of the tubes is given above, in which it is demonstrated that there certainly is being created a flow through the tubes because of the less flow resistance within the tubes than in the soil outside, but this flow is very small, having a magnitude in order of $0.5-5 \mathrm{~mm}$ per second. Even though this is 5-10 times larger than the flow velocity induced by tidal flow in the surrounding soil for the case of fine soil, it will have no drainage effect because the tubes occupy a very small fraction of the area under consideration: the changes in drainage capacity is only in the order of one per thousand, corresponding to a change in tidal amplitude from $1.000 \mathrm{~m}$ to $0.999 \mathrm{~m}$. The impact of the combination of salt and fresh water is modeled by a numerical model, and gives similar results as those described above. The presence of permeable and impermeable layers is also discussed, and it is concluded that you need very special configurations of these layers to provoke any impact from the tubes.

Morphodynamic fingerprint: no local accretion around the tubes - or tube row- has been observed. On a larger scale it is concluded, that any kind of interpretation is impossible because possible impact from the tubes is overshadowed by natural fluctuations.

Link to detailed reports with all the data materiel: http://www.trm.dk/sw194114.asp. Other ongoing projects: Hillsboro Beach, Florida, where the local authorities also seem to be in favor of continuing with PEM solution and Francis Bay, South Africa, where the inner part of the beach raised significantly already after 6 days, see http://www.dna-online.co.za/sfbra/Beach-Project.htm.

\section{References:}

Bowman, D. Ferfi, S. and Pranzini, E. 2007 Efficacy of beach dewatering-Alassio, Italy. Coastal Engineering 54, pp 791-800.

Diersch, H.-J.G., FEFLOW 5.3, Users' Manual. 2006 WASY software, Institute for Water Resources Planning and Systems Research

Lundgren and Brinch Hansen 1965 Geoteknik, Teknisk Forlag, Copenhagen 
